\title{
Drinking water is a significant predictor of Blastocystis infection among rural Malaysian primary schoolchildren
}

\author{
AWATIF M. ABDULSALAM ${ }^{1}$, INIT ITHOI ${ }^{1}$, HESHAM M. AL-MEKHLAFI ${ }^{1,3}$, \\ ABDULHAMID AHMED ${ }^{1}$, JOHARI SURIN ${ }^{1}$ and JOON-WAH MAK ${ }^{2}$ \\ ${ }^{1}$ Department of Parasitology, Faculty of Medicine, University of Malaya, 50603 Kuala Lumpur, Malaysia \\ ${ }^{2}$ School of Postgraduate Studies and Research, International Medical University, Bukit Jalil, 57000 Kuala Lumpur, \\ Malaysia \\ ${ }^{3}$ Department of Parasitology, Faculty of Medicine and Health Sciences, Sana'a University, Sana'a, Yemen
}

(Received 3 December 2011; revised 20 Fanuary and 3 February 2012; accepted 4 February 2012)

\section{SUMMARY}

Blastocystis infection has a worldwide distribution especially among the disadvantaged population and immunocompromised subjects. This study was carried out to determine the prevalence and the association of Blastocystis infection with the socio-economic characteristics among 300 primary schoolchildren, living in rural communities in Lipis and Raub districts of Pahang state, Malaysia. Stool samples were collected and examined for the presence of Blastocystis using direct smear microscopy after in vitro cultivation in Jones' medium. The overall prevalence of Blastocystis infection was found to be as high as $25 \cdot 7 \%$. The prevalence was significantly higher among children with gastrointestinal symptoms as compared to asymptomatic children $\left(x^{2}=4 \cdot 246 ; P=0 \cdot 039\right)$. Univariate and multivariate analyses showed that absence of a piped water supply $(\mathrm{OR}=3 \cdot 13 ; 95 \% \mathrm{CI}=1 \cdot 78,5 \cdot 46 ; P<0 \cdot 001)$ and low levels of mothers' education $(\mathrm{OR}=3 \cdot 41 ; 95 \% \mathrm{CI}=1 \cdot 62,7 \cdot 18$; $P<0.01)$ were the significant predictors of Blastocystis infection. In conclusion, Blastocystis is prevalent among rural children and the important factors that determine the infection were the sources of drinking water and mothers' educational level. Interventions with provision of clean water supply and health education especially to mothers are required.

Key words: Blastocystis, predictors, drinking water, schoolchildren, Malaysia.

\section{INTRODUCTION}

Blastocystis, an intestinal protozoan, has a worldwide distribution and is often the most commonly reported human intestinal protozoan in children and adults in developing countries (Stenzel and Boreham, 1996; Tan, 2008). Infection with Blastocystis is believed to be associated with gastrointestinal symptoms including acute or chronic diarrhoea, which is sometimes self-limited, and tenesmus, pruritus, anorexia, nausea, vomiting, fever and eosinophilia (Leder et al. 2005; Sohail and Fischer, 2005). Several forms of Blastocystis are observed in in vitro culture (i.e. vacuolar, avacuolar, multivacuolar, granular, amoeboid, and cyst), the vacuolar form being mostly recognized through microscopy. The fecal-oral route is considered the main mode of transmission of Blastocystis in day-care centres, institutions and among residents of small communities (Stenzel and Boreham, 1996). Many reports have shown that poor hygiene, consumption of contaminated food or water and close contact with animals are significant risk factors of Blastocystis infection (Nimir, 1993; Tan,

\footnotetext{
* Corresponding author: Department of Parasitology, Faculty of Medicine, University of Malaya, 50603 Kuala Lumpur, Malaysia. Tel: +60379674767 . Fax: +60379674754. E-mail: init@um.edu.my, init.ithoi@ gmail.com
}

2004; Yoshikawa et al. 2009; Baldursson and Karanis, 2011).

In Malaysia, there is increasing concern about Blastocystis infection as previous studies have shown that Blastocystis is prevalent among urban and rural people and in water of rivers from recreational areas (Noor Azian et al. 2007; Ithoi et al. 2011). However, data on the predictors of infection is largely lacking. Therefore, this study was carried out to determine the prevalence of Blastocystis and to investigate its association with the socio-economic characteristics of schoolchildren in a rural community in the Pahang State, Malaysia.

MATERIALS AND METHODS

\section{Study areas and subjects}

This cross-sectional study was conducted between April and August 2010 among rural schoolchildren aged 6-13 years in Lipis (located about $230 \mathrm{Km}$ northeast of Kuala Lumpur) and Raub (located about $190 \mathrm{Km}$ northeast of Kuala Lumpur) districts of Pahang state, Malaysia. In Lipis (longitude $102.03^{\circ} \mathrm{E}$, latitude $\left.4.11^{\circ} \mathrm{N}\right), 2$ primary schools were involved in this study; the National School of Gahai (for Malay, with a total enrolment of 96 pupils) and the National School of Kuala Koyan (for Aborigines, 
with a total enrolment of 160 pupils). Similarly, 2 primary schools in Raub (longitude $101.52^{\circ} \mathrm{E}$, latitude $3.48^{\circ} \mathrm{N}$ ) were involved, these being the National School of Lubuk Kulit (for Malay, with a total enrolment of 100 pupils) and the National School of Satak (for Aborigines with a total enrolment of 363 pupils). Each school is located approximately at the centre of the villages.

The villages of Malay and the aboriginal population are close to each other and almost all houses had an electricity supply. Houses of aboriginal people are made of wood or bamboo in which environmental sanitation, as well as personal hygiene, are poor. On the other hand, the housing conditions of Malay people are better; the traditional Malay houses are timber houses raised on stilts with wooden or bamboo walls. However, there are many houses built of bricks and concrete in the Malay villages. As in other parts of Malaysia, the climate is equatorial with hot-humid conditions and rainfall throughout the year. The vegetation is the thick rain forest type and there are few water streams in the area.

All schoolchildren attending these schools during the survey visits were invited to participate in this study. We observed a higher absenteeism rate among aboriginal compared to Malay schoolchildren in which more than one third of the schoolchildren were absent. Although, a sample size of 247 children was estimated to give the study at least $95 \%$ power at $5 \%$ level of significance, we invited all children in these schools to participate (universal sampling). Hence, a total of 300 ( $70 \%$ of those present during the visits 300/429) primary schoolchildren (150 males and 150 females) aged 6-12 years have agreed to participate in this study.

\section{Questionnaire}

A pre-tested questionnaire was used for the collection of demographic and socio-economic data, environmental factors, and history of gastrointestinal symptoms (Al-Mekhlafi et al. 2008). The children and their parents were interviewed by a well-trained assistant, in their home settings, to fill in the questionnaire.

\section{Detection of Blastocystis}

Fresh faecal samples were collected into wide-mouth, screw-capped containers and then transported to the Laboratory, Department of Parasitology, University of Malaya, Kuala Lumpur. Approximately $50 \mathrm{mg}$ of feces were inoculated into a $15-\mathrm{ml}$ screw-capped tube containing $5.0 \mathrm{ml}$ of complete Jones' medium (Ithoi, 1999). All inoculated tubes were tightly closed, placed in a rack and incubated at $37^{\circ} \mathrm{C}$. The medium in each of these tubes was replaced with the new complete Jones' medium every alternate day starting from day 2 of cultivation. This was carried out by discarding about $4.0 \mathrm{ml}$ of the medium at the top level (without disturbing the pellet) and replaced by $4.0 \mathrm{ml}$ of new complete Jones' medium. The presence of Blastocystis was observed daily for 14 days of cultivation, by placing 1 drop of cultured sediment onto a glass slide, covered with a cover-slip and viewed (X100 and X400 objectives) under light microscopy (Olympus BX51). Various sizes of Blastocystis cells $(2-15 \mu \mathrm{m})$ were seen as vacuolar (most common), granular (many especially in old stool culture tubes), amoeboid (vacuolar or granular with pseudopodia) and cyst forms. Some of these morphologies are shown in Fig. 1. The number of positive tubes for Blastocystis was then recorded.

\section{Statistical analysis}

Data analysis was performed using the Statistical Package for Social Sciences for Windows SPSS (version 13, September 2004). A proportion was used to present the prevalence of infections and other categorical variables. The Chi-square test was used to test for associations between independent variables and Blastocystis infection. A multiple logistic regression model was performed to identify the significant predictors of infection. $P<0.05$ was considered statistically significant.

\section{Ethical issues}

Prior to the stool collection, the objectives of this study were explained to the headmasters, teachers and children, and informed verbal consent was obtained. The protocol of this study was approved by the Medical Ethics Committee of the University of Malaya Medical Centre, Kuala Lumpur.

\section{RESULTS}

A total of 300 primary schoolchildren (150 males and 150 females, aged $6-12$ years, median age $=9$ years, Interquartile Range $=9-11$ years) participated in this study. General characteristics of the subjects, including the demographic and socio-economic profiles, are shown in Table 1. In comparison, household income and the percentage of fathers who have at least 6 years of formal education are significantly higher among Malay compared to aboriginal people. On the other hand, the percentage of working aboriginal mothers (mostly farmers or rubber tapper) was significantly higher than in Malay people $(P<0 \cdot 05)$. However, there was no significant difference in the percentage of mothers with at least 6 years of formal education between both populations. The majority of aboriginal worked as farmers, and almost half of the Malay were either government employees or have their own business. 


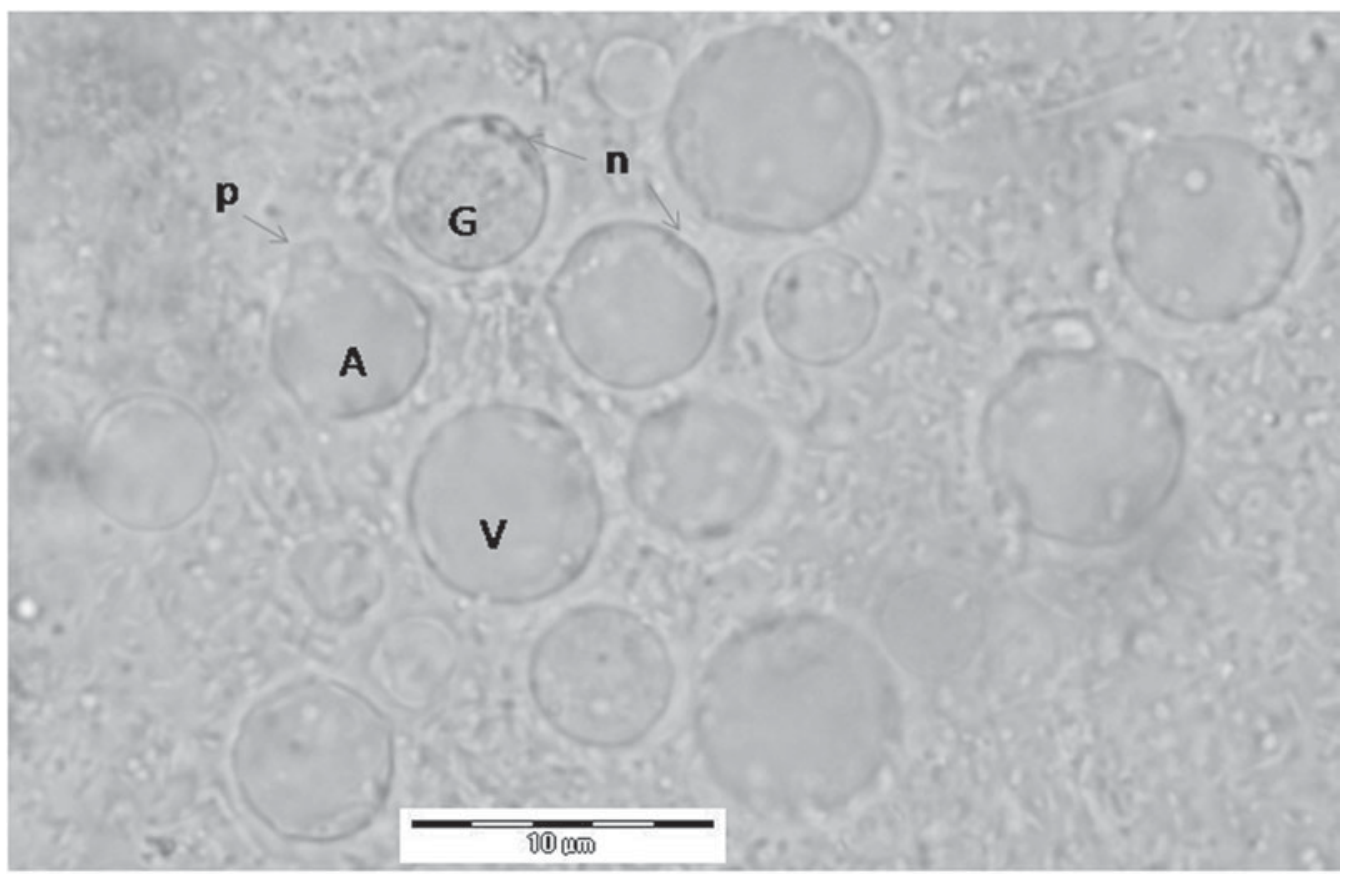

$\mathrm{V}=$ vacuolar form, $\mathrm{G}$ = vacuole with granules (granular form), $\mathrm{A}=$ vascular with pseudopodia (amoeboid form), $\mathrm{n}=$ sandy nuclei, $\mathrm{p}=$ pseudopodia

Fig. 1. Various forms of Blastocystis cells (X400) from culture of stool samples.

Table 1. General characteristics of schoolchildren participating in this study $(n=300)$

\begin{tabular}{ll}
\hline \hline & $\begin{array}{l}\text { Frequency } \\
(\%)\end{array}$ \\
Characteristics & \\
\hline Age groups (years) & $50 \cdot 7$ \\
$\quad \quad 10$ years & $49 \cdot 3$ \\
$\quad>10$ years & \\
Gender & $50 \cdot 0$ \\
Female & $50 \cdot 0$ \\
Male & \\
Ethnicity & $39 \cdot 7$ \\
$\quad$ Malay & $60 \cdot 3$ \\
$\quad$ Aborigines & \\
Socio-economic status & $77 \cdot 0$ \\
$\quad$ Fathers' education (at least 6 years) & $78 \cdot 7$ \\
Mothers' education (at least 6 years) & $44 \cdot 3$ \\
$\quad$ Low household income (<RM* 500) & $42 \cdot 0$ \\
Working mothers & $64 \cdot 3$ \\
Large family (>7 members) & $52 \cdot 7$ \\
$\quad$ Supplied with piped water & $71 \cdot 7$ \\
$\quad$ Presence of animals at household & \\
\hline \hline
\end{tabular}

* RM, Malaysian ringgits (US\$1.00= RM3.00).

\section{Prevalence and distribution of Blastocystis infection}

The overall prevalence of Blastocystis was $25 \cdot 7 \%$ $(77 / 300)$, it was more frequent in males than females though this difference was not statistically significant $\left(x^{2}=2 \cdot 950 ; P=0 \cdot 086\right)$. Similarly, there was no significant difference in the rate of infection according to age $\left(\chi^{2}=0.031 ; P=0 \cdot 860\right)$. Moreover, the prevalence of Blastocystis was higher among the aboriginal children than the Malay but the difference was also not statistically significant $(29 \cdot 3 \%$ compared to $\left.20 \cdot 2 \% ; \quad x^{2}=3 \cdot 126 ; \quad P=0 \cdot 077\right)$. With regards to the symptoms, the prevalence of Blastocystis was significantly higher among the participants who had gastrointestinal symptoms as compared to asymptomatic participants $(34 \cdot 7 \%$ compared to $22 \cdot 7 \%$; $\left.x^{2}=4 \cdot 246 ; \quad P=0.039\right)$, with abdominal pain and diarrhoea as the most common symptoms (Fig. 2). Stool specimens were also screened for the presence of other intestinal parasitic infections, and the children were found to be infected with Trichuris trichiura (47·0\%), Ascaris lumbricoides (20.7\%), hookworm (1.7\%), Giardia duodenalis $(15 \cdot 3 \%)$ and Entamoeba histolytica/dispar (4·3\%). Except giardiasis, there was no significant association between these infections and the gastrointestinal symptoms $(P>0 \cdot 05)$. Regarding co-infections, only $2 \cdot 3 \%$ of the children had both Blastocystis and $G$. duodenalis, while $5 \cdot 3 \%$ had Blastocystis with Ascaris and/or Trichuris. However, about half $(49 \cdot 4 \% ; 38 / 77)$ of the Blastocystis infections were single infections, and were also found to be associated significantly with the gastrointestinal symptoms $\left(x^{2}=4 \cdot 861 ; P=0 \cdot 027\right)$.

\section{Predictors of Blastocystis infection}

Variables that may be associated with the prevalence of Blastocystis infection were analysed using univariate and multivariate analyses, and the results are presented in Table 2. The results of univariate analysis showed that the absence of a piped water supply $\left(x^{2}=14.844 ; P<0 \cdot 001\right)$ and the low level of mothers' education $\left(x^{2}=9 \cdot 097 ; \quad P<0 \cdot 01\right)$ were 


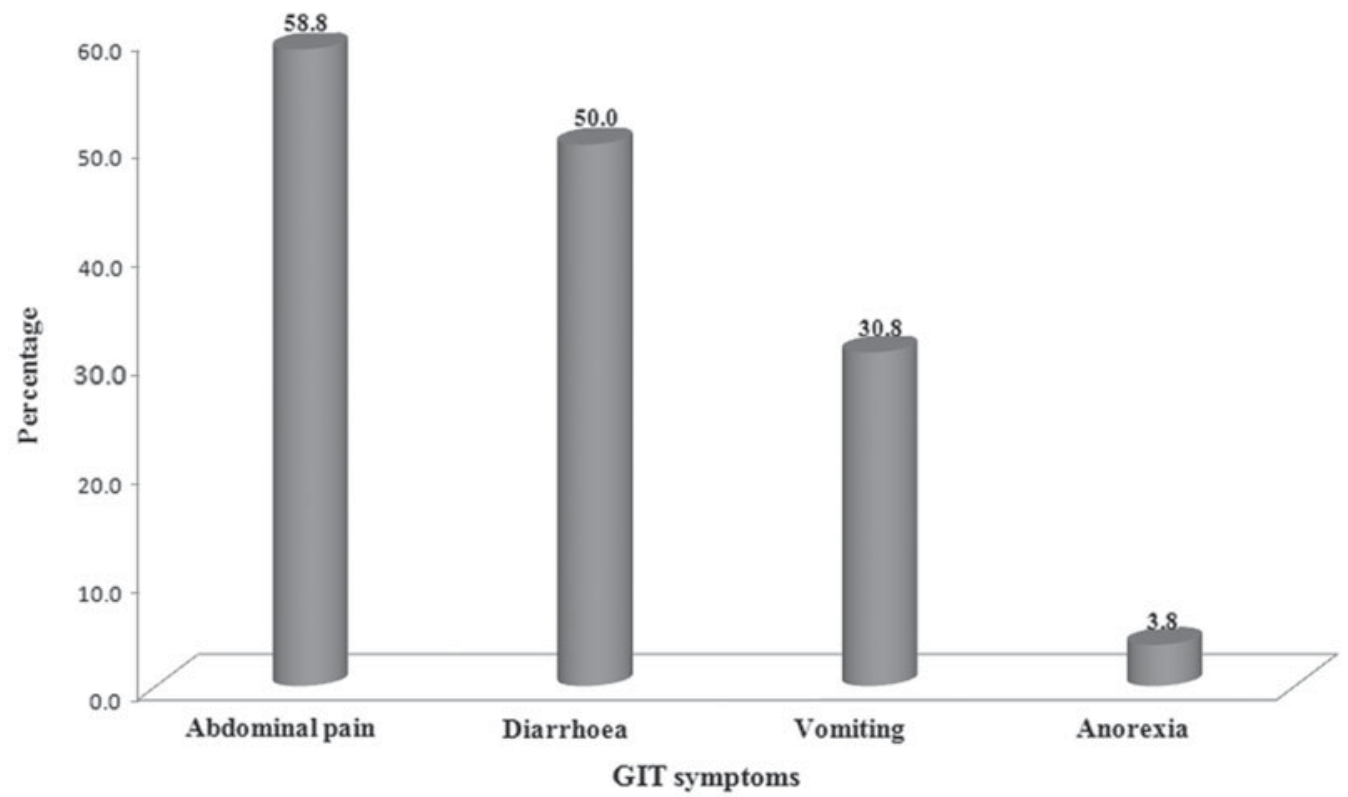

Fig. 2. Distribution of gastrointestinal symptoms among Blastocystis-infected schoolchildren.

significantly associated with the prevalence of infection. On the other hand, other variables including age, sex, race, family size, family monthly income, parental employment status and the presence of animals at the household showed no significant association with the prevalence of Blastocystis infection. Logistic regression analysis confirmed that the absence of a piped water supply and the low level of mothers' education were the significant predictors for the occurrence of Blastocystis infection. Schoolchildren who do not have a tap water facility were more than 3 times as likely to be infected $(\mathrm{OR}=3 \cdot 13$; $95 \% \mathrm{CI}=1 \cdot 78,5 \cdot 46 ; P<0 \cdot 001)$. Likewise, children of mothers with a low level of education were more likely to be infected with Blastocystis as compared to those of mothers with at least 6 years of formal education $(\mathrm{OR}=3 \cdot 41 ; 95 \% \mathrm{CI}=1 \cdot 62,7 \cdot 18$; $P<0 \cdot 01)$.

\section{DISCUSSION}

In the present study, the infection rate of Blastocystis was $25 \cdot 6 \%$, which is within the range of prevalence rate of previous local reports. Several Malaysian researchers noted that the infection rate of this protozoan was between $1 \cdot 1 \%$ and $4 \cdot 4 \%$ in children with diarrhoea (Sinniah and Rajeswari, 1994; Menon et al. 1999). Recently, an epidemiological survey showed a prevalence of $52.3 \%$ in Aborigines living in Pos Senderut, Pahang (Noor Azian et al. 2007). Pos Senderut is a remote aboriginal settlement located deep in the jungle with no road access, electricity, piped water and sanitation facilities and this could explain the higher prevalence of Blastocystis and other intestinal parasites. Comparing our findings with studies from other countries showed that the prevalence reported by the present study was similar to those reported among children in Iran $(28 \cdot 2 \%)$ and Colombia (22.4\%) (Daryani et al. 2006; Boeke et al. 2010). However, it is higher than that among schoolaged children from Thailand and India (Yaicharoen et al. 2006; Rayan et al. 2010). By contrast, considerably higher prevalence rates of $48.7 \%$ and $40 \cdot 7 \%$ were reported among Philippians and Argentinean children, respectively (Baldo et al. 2004; Gamboa et al. 2011). Our findings showed no significant difference in the prevalence of Blastocystis infection according to age and gender of the participants, and this is consistent with the results of previous reports (Noor Azian et al. 2007; Leelayoova et al. 2008; Cook et al. 2009).

Our findings also showed that the prevalence of infection was higher among aboriginal schoolchildren than their Malay peers and this could be attributed to the poor living conditions and sociobehavioural factors. The Aborigines were previously living in isolated huts without electricity, toilet and water supply, located near to the stream in the forest. They were then re-settled along the water streams and their houses were equipped with electricity and a toilet. Some of the houses have a piped water supply. Nevertheless, the Aborigines preferred defecating at the site of the stream, and used water from streams for most of their daily activities (swimming, cooking, drinking, bathing and washing). This practice of defecating near the streams by the residents (especially children) in Lipis district, Pahang has been noted by other workers (Al-Mekhlafi et al. 2008). Household animals such as dogs, cats and chickens roamed freely in and out of the houses and water streams, which could also contribute to the contamination of water sources. The occurrence of Blastocystis in water from wells and from the rain is not known but Blastocystis, Cryptosporidium and 
Table 2. Univariate and multivariate analyses of potential predictors associated with Blastocystis infection among rural schoolchildren in Pahang, Malaysia $(n=300)$

(OR, odds ratio; CI, confidence interval.)

\begin{tabular}{|c|c|c|c|}
\hline \multirow[b]{2}{*}{ Variables } & \multicolumn{3}{|c|}{ Blastocystis infection } \\
\hline & Prevalence $(\%)$ & OR $(95 \% \mathrm{CI})$ & $P$ \\
\hline \multicolumn{4}{|l|}{ Age } \\
\hline$\leqslant 10$ years & $26 \cdot 0$ & $1 \cdot 05(0 \cdot 60,1 \cdot 85)$ & $0 \cdot 860$ \\
\hline$>10$ years & $25 \cdot 0$ & 1 & \\
\hline \multicolumn{4}{|l|}{ Gender } \\
\hline Male & $30 \cdot 0$ & $1 \cdot 58(0 \cdot 94,2 \cdot 67)$ & $0 \cdot 086$ \\
\hline Female & $21 \cdot 3$ & 1 & \\
\hline \multicolumn{4}{|l|}{ Ethnicity } \\
\hline Aborigines & $29 \cdot 3$ & $1 \cdot 64(0 \cdot 95,2 \cdot 84)$ & $0 \cdot 077$ \\
\hline Malay & $20 \cdot 2$ & 1 & \\
\hline \multicolumn{4}{|l|}{ Fathers' education } \\
\hline No formal education & $31 \cdot 9$ & $1 \cdot 50(0 \cdot 83,2 \cdot 70)$ & $0 \cdot 178$ \\
\hline$\geqslant 6$ years formal education & $23 \cdot 8$ & 1 & \\
\hline \multicolumn{4}{|l|}{ Mothers' education } \\
\hline No formal education & $45 \cdot 9$ & $2 \cdot 88(1 \cdot 15,5 \cdot 84)$ & $0 \cdot 003^{\mathrm{a}, \mathrm{b}}$ \\
\hline$\geqslant 6$ years formal education & $22 \cdot 8$ & 1 & \\
\hline \multicolumn{4}{|l|}{ Mothers' employment status } \\
\hline Not working (housewives) & $25 \cdot 3$ & $0.95(0 \cdot 57,1 \cdot 61)$ & $0 \cdot 860$ \\
\hline Working (public/private) & $26 \cdot 2$ & 1 & \\
\hline \multicolumn{4}{|l|}{ Household income } \\
\hline$\leqslant \mathrm{RM}^{*} 500 /$ month $($ low $)$ & $29 \cdot 3$ & $1 \cdot 41(0 \cdot 84,2 \cdot 37)$ & $0 \cdot 196$ \\
\hline > RM500/month & $22 \cdot 8$ & 1 & \\
\hline \multicolumn{4}{|l|}{ Family size } \\
\hline$>7$ members (large) & $31 \cdot 8$ & $1.63(0.98,2 \cdot 76)$ & $0 \cdot 071$ \\
\hline$\leqslant 7$ members & $22 \cdot 3$ & 1 & \\
\hline \multicolumn{4}{|l|}{ Presence of toilet in house } \\
\hline No & $26 \cdot 0$ & $1 \cdot 07(0 \cdot 59,1 \cdot 93)$ & $0 \cdot 814$ \\
\hline Yes & $24 \cdot 7$ & 1 & \\
\hline \multicolumn{4}{|l|}{ Source of drinking water } \\
\hline Untreated (stream, rain, well) & $35 \cdot 9$ & $2 \cdot 85(1 \cdot 65,4 \cdot 89)$ & $<0 \cdot 001^{\mathrm{a}, \mathrm{b}}$ \\
\hline Treated (piped) & $16 \cdot 5$ & 1 & \\
\hline \multicolumn{4}{|l|}{ Presence of animals at household } \\
\hline Yes & $24 \cdot 7$ & $0 \cdot 83(0 \cdot 47,1 \cdot 46)$ & $0 \cdot 522$ \\
\hline No & $28 \cdot 2$ & 1 & \\
\hline
\end{tabular}

a Significant association, $P<0 \cdot 05$.

b Confirmed as significant predictors by logistic regression analysis.

* RM, Malaysian ringgits.

Giardia contaminated surface water from Malaysia due to the exposure with infected feces from local communities (human and animals) that live surrounding the streams have been reported (Azman et al. 2009; Ithoi et al. 2011). Blastocystis is transmitted by the fecal-oral route among family members, patients and staff of day-care centres, and residents of small communities that lack access to proper sanitation (Stenzel and Boreham, 1996). As evidence of zoonotic transmission, several molecular studies have identified Blastocystis in a wide range of animals and have reported that most of the Blastocystis isolates from humans and animals including monkeys, chickens, cattle, rats and pigs are genetically identical (Yoshikawa et al. 2003, 2004, 2009).
As the first report from Malaysia, our study indicates that children who have no access to a piped water supply are more prone to get Blastocystis infection, and this provides further evidence for waterborne transmission of Blastocystis. Few studies have implicated contaminated water as a source of Blastocystis infections (Taamasri et al. 2000; Li et al. 2007; Leelayoova et al. 2008; Eroglu and Koltas, 2010; Baldursson and Karanis, 2011). This is not surprising since the transmissible form of the parasite is the water-resistant cyst (Tan, 2004). Blastocystis cysts were reportedly able to survive in water for up to 19 days at a normal temperature, but are fragile at extremes of heat and cold, and in common disinfectants (Zaman et al. 1995; Moe et al. 1996). During the visits to the villages, we observed that 
almost half of the households among both communities (the Aborigine and Malay) used water from the streams, wells and rain with or without further treatment by filtration or boiling. River water can be highly exposed to contamination with infected feces from wild/domestic animals and humans living around the river (Azman et al. 2009; Ithoi et al. 2011). Therefore, drinking unboiled surface water from streams is strongly believed to be the main risk factor for Blastocystis infection, as shown in this study.

Leelayoova et al. (2008) described the possibility of waterborne transmission of Blastocystis by identifying the same genotype of Blastocystis in fecal specimens collected from schoolchildren and in the drinking water provided in schools. A study conducted in China, revealed a high infection rate $(32 \cdot 6 \%)$ and found that the consumption of raw water plants and drinking unboiled water were predictors for Blastocystis infection (Li et al. 2007). Moreover, in a study among pre-school children from Jordan, the prevalence rate of Blastocystis infection was $25 \%$ and contaminated water was implicated as a major source of infection (Nimri, 1993). In a worldwide review on waterborne outbreaks of parasitic protozoan infections, Karanis et al. (2007) documented 325 outbreaks since the 1950 s and revealed that the majority of outbreaks were reported in the USA and Europe with Giardia and Cryptosporidium being the predominant protozoa followed by Entamoeba, Blastocystis, Cyclospora, Toxoplasma, Microsporidia and free-living amoebas. Indicating a dramatic increase in the number of waterborne outbreaks caused by those protozoa, Baldursson and Karanis (2011) showed that 199 outbreaks have been reported between 2004 and 2010 with $40 \cdot 2 \%$ and $30 \cdot 6 \%$ of the outbreaks occurring in New Zeeland and North America, respectively.

Another significant finding that was associated with the risk of Blastocystis infection was the low level of maternal education. Children of mothers with less than 6 years of formal education were almost 3 times more likely to be infected with Blastocystis. It is well documented that education of the family, particularly the mothers, has an important role in preventing intestinal parasitic infections among children (Okyay et al. 2004). Daryani et al. (2006) reported that prevalence of Blastocystis in children of working mothers was less than those of non-working mothers. They assumed that a higher educational level in employed mothers played an important role in hygienic education of their children. In contrast, other studies found no association between the mother's educational level and the rate of Blastocystis infection (Leelayoova et al. 2008; Boeke et al. 2010).

Subsequently, infection of Blastocystis, as either single or multiple infections, was found to be significantly associated with gastrointestinal symptoms among these schoolchildren with abdominal pain $(58 \cdot 8 \%)$ and diarrhoea $(50.0 \%)$ being the common symptoms. To date, the pathogenic role of Blastocystis is still controversial (Tan et al. 2010). Numerous clinical and epidemiological studies concluded that Blastocystis is a commensal organism and probably is not responsible for clinical symptoms when detected (Sun et al. 1989). On the other hand, many studies have also shown the association of some gastrointestinal symptoms with the infection, and have suggested a positive correlation between the parasite density and symptoms (Qadri et al. 1989; Galantowicz et al. 1993; Nimri and Batchoun, 1994; Kaya et al. 2007). In a large-scaled study aimed at determining the prevalence and clinical importance of Blastocystis among 12136 patients in Saudi Arabia, $17.5 \%$ of the patients were infected and almost half of them were symptomatic with abdominal pain being the most common symptom $(87 \cdot 9 \%)$ followed by constipation (32.2\%) and diarrhoea (23.4\%) (Qadri et al. 1989). In another study conducted among hospitalized Turkish patients without any other coinfecting pathogens, higher rates of symptoms were present among Blastocystis-infected children, abdominal pain was present in $76.9 \%$, diarrhoea in $50 \%$ and distention in $32 \cdot 6 \%$, indicating an association between parasite density and pathology (Kaya et al. 2007). Moreover, several studies found a higher incidence of Blastocystis infection among immunocompromised individuals, including AIDS patients and individuals with cancer (Horiki et al. 1999; Tasova et al. 2000; Kurniawan et al. 2009). Besides that, extraintestinal manifestations were reported as invasive Blastocystis infections in 2 recent studies and a debate over the issue that Blastocystis is an opportunistic pathogen has began ( $\mathrm{Hu}$ et al. 2008; Janarthanan et al. 2011).

In conclusion, this study revealed that Blastocystis infection exists among primary schoolchildren in rural Peninsular Malaysia. Water supply and maternal education were the main determinants of the infection. Hence, improvement of sanitary facilities and quality of drinking water, public education and health promotion should be considered to prevent and control this infection.

\section{ACKNOWLEDGEMENTS}

The authors would like to thank all children and their parents for their participation in this study. Thanks are due to headmasters and teachers of the respective schools at which specimens were collected, for their kind help and cooperation.

\section{F I NANCIAL SUPPORT}

This study was supported by a research grant from University of Malaya (No. RG187/10HTM and PS230/ 2010B), Kuala Lumpur, Malaysia. 


\section{REFERENCES}

Al-Mekhlafi, M.H., Surin, J., Atiya, A.S., Ariffin, W. A., Mahdy, M. A. K. and Abdullah, H. C. (2008). Pattern and predictors of soil-transmitted helminth re-infection among Aboriginal schoolchildren in rural peninsular Malaysia. Acta Tropica 107, 200-204

Azman, J., Init, I. and Wan Yusoff, W. S. (2009). Occurrence of Giardia and Cryptosporidium oocysts in the river water of two recreational areas in Selangor, Malaysia. Tropical Biomedicine 26, 289-302.

Baldo, E. T., Belizario, V.Y., De Leon, W. U., Kong, H.H. and Chung, D. I. (2004). Infection status of intestinal parasites in children living in residential institutions in Metro Manila, the Philippines. Korean Fournal of Parasitology 42, 67-70.

Baldursson, S. and Karanis, P. (2011). Waterborne transmission of protozoan parasites: review of worldwide outbreaks - an update 2004-2010. Water Research 45, 6603-6614.

Boeke, C. E., Mora-Plazas, M., Forero, Y. and Villamor, E. (2010). Intestinal protozoan infections in relation to nutritional status and gastrointestinal morbidity in Colombian schoolchildren. Fournal of Tropical Pediatrics 56, 299-306.

Cook, D. M., Swanson, R. C., Eggett, D. L. and Booth, G. M. (2009). A retrospective analysis of prevalence of gastrointestinal parasites among schoolchildren in the Palajunoj Valley of Guatemala. Fournal of Health, Population and Nutrition 27, 31-41.

Daryani, A., Barmaki, N., Ettehad, G. H., Sharif, M., Nemati, A. and Ziaei, H. (2006). A cross-sectional study of Blastocystis hominis in primary schoolchildren, Northwest Iran. International Fournal of Tropical Medicine 1, 53-57.

Eroglu, F. and Koltas, I. S. (2010). Evaluation of the transmission mode of B. hominis by using PCR method. Parasitology Research 107, 841-845

Galantowicz，B. B., Illueca，M. D., Levy, J., Rayburn, J. L. and Weinstock, D. J. (1993). Neonatal Blastocystis hominis diarrhea. Pediatric Infectious Disease Fournal 12, 345-346.

Gamboa, M. I., Navone, G. T., Orden, A. B., Torres, M. F., Castro, L. E. and Oyhenart, E. E. (2011). Socio-environmental conditions, intestinal parasitic infections and nutritional status in children from a suburban neighborhood of La Plata, Argentina. Acta Tropica 118, 184-189. Hakim, S. L., Gan, C.C., Malkit, K., Azian, M. N., Chong, C. K., Shaari, N., Zainuddin, W., Chin, C. N., Sara, Y. and Lye, M. S. (2007). Parasitic infections among Orang Asli (Aborigine) in the Cameron Highlands, Malaysia. Southeast Asian Fournal of Tropical Medicine and Public Health 38, 415-419.

Horiki, N., Kaneda, Y., Maruyama, M., Fujita, Y. and Tachibana, H. (1999). Intestinal blockage by carcinoma and Blastocystis hominis infections. The American Fournal of Tropical Medicine and Hygiene 60, 400-402.

Hu, K. C., Lin, C. C., Wang, T.E., Liu, C.Y., Chen, M. J. and Chang, W. H. (2008). Amoebic liver abscess or is it? Gut 57, 627.

Ithoi, I. (1999). Immunology and molecular studies of Blastocystis hominis isolates from symptomatic and asymptomatic patients. Ph.D. thesis. University of Malaya, Kuala Lumpur, Malaysia.

Ithoi, I., Azman, J., Mak, J. W., Wan Yusoff, W. S. and Rohela, M. (2011). Occurrence of Blastocystis in water of two rivers from recreational areas in Malaysia. Fournal of Parasitology Research 2011, doi: 10.1155/2011/ 123916.

Janarthanan, S., Khoury, N. and Antaki, F. (2011). An unusual case of invasive Blastocystis hominis infection. Endoscopy 43, E185-E186.

Karanis, P., Kourenti, C. and Smith, H. (2007). Waterborne transmission of protozoan parasites: a worldwide review of outbreaks and lessons learnt. Fournal of Water and Health 5, 1-38.

Kaya, S., Cetin, E. S., Aridogan, B. C., Arikan, S. and Demirci, M. (2007). Pathogenicity of Blastocystis hominis, a clinical re-evaluation. Acta parasitologica Turcica 31, 184-187.

Kurniawan, A., Karyadi, T., Dwintasari, S. W., Sari, I. P., Yunihastuti, E., Djauzi, S. and Smith, H. V. (2009). Intestinal parasitic infections in HIV/AIDS patients presenting with diarrhoea in Jakarta, Indonesia. Transactions of the Royal Society of Tropical Medicine and Hygiene 103, 892-898.

Leder, K., Hellard, M.E., Sinclair, M. I., Fairley, C. K., Wolfe, R. (2005). No correlation between clinical symptoms and Blastocystis hominis in immunocompetent individuals. Fournal of Gastroenterology and Hepatology 20, 1390-1394.

Leelayoova, S., Siripattanapipong, S., Thathaisong, U., Naaglor, T., Taamasri, P., Piyaraj, P. and Mungthin, M. (2008). Drinking water: a possible source of Blastocystis spp. subtype 1 infection in schoolchildren of a rural community in central Thailand. The American Fournal of Tropical Medicine and Hygiene 79, 401-406.

Li, L. H., Zhou, X. N., Du, Z. W., Wang, X. Z., Wang, L. B., Jiang, J. Y. Yoshikawa, H., Steinmann, P., Utzinger, J., Wu, Z., Chen, J. X., Chen, S. H. and Zhang, L. (2007). Molecular epidemiology of human Blastocystis in a village in Yunnan province, China. Parasitology International 56, 281-286.

Menon, B. S., Abdullah, M., Mahamud, F. and Singh, B. (1999). Brief report: Intestinal parasites in Malaysian children with cancer. Fournal of Tropical Pediatrics 45, 241-242.

Moe, K. T., Singh, M., Howe, J., Ho, L. C., Tan, S. W., Ng, G.C., Chen, X. Q. and Yap, E. H. (1996). Observations on the ultrastructure and viability of the cystic stage of Blastocystis hominis from human feces. Parasitology Research 82, 439-444.

Nimri, L.F. (1993). Evidence of an epidemic of Blastocystis hominis infections in preschool-children in Northern Jordan. Fournal of Clinical Microbiology 31, 2706-2708.

Nimri, L. and Batchoun, R. (1994). Intestinal colonization of symptomatic and asymptomatic schoolchildren with Blastocystis hominis. Fournal of Clinical Microbiology 32, 2865-2866.

Noor Azian, M.Y., San, Y.M., Gan, C. C., Yusri, M.Y., Nurulsyamzawaty, Y., Zuhaizam, A.H., Maslawaty, M. N. Norparina, I. and Vythilingam, I. (2007). Prevalence of intestinal protozoa in an aborigine community in Pahang, Malaysia. Tropical Biomedicine 24, 55-62.

Okyay, P., Ertug, S., Gultekin, B., Onen, O. and Beser, E. (2004). Intestinal parasites prevalence and related factors in school children, a western city sample-Turkey. BMC Public Health 4, 64.

Qadri, S. M., al-Okaili, G. A. and al-Dayel, F. (1989). Clinical significance of Blastocystis hominis. Fournal of Clinical Microbiology 27, 2407-2409.

Rayan, P., Verghese, S. and McDonnell, P. (2010). Geographical location and age affects the incidence of parasitic infestations in schoolchildren. Indian Fournal of Pathology and Microbiology 53, 498-504. Sinniah, B. and Rajeswari, B. (1994). Blastocystis hominis infection, a cause of human diarrhea. Southeast Asian Fournal of Tropical Medicine and Public Health 25, 490-493.

Sohail, M. R. and Fischer, P. R. (2005). Blastocystis hominis and travelers. Travel Medicine and Infectious Disease 3, 33-38.

Stenzel, D. J. and Boreham, P. F. (1996). Blastocystis hominis revisited Clinical Microbiology Reviews 9, 563-584.

Sun, T., Katz, S., Tanenbaum, B. and Schenone, C. (1989). Questionable clinical significance of Blastocystis hominis infection. American Fournal of Gastroenterology 84, 1543-1547.

Taamasri, P., Mungthin, M., Rangsin, R., Tongupprakarn, B., Areekul, W. and Leelayoova, S. (2000). Transmission of intestinal blastocystosis related to the quality of drinking water. Southeast Asian Fournal of Tropical Medicine and Public Health 31, 112-117.

Tan, K. S., Mirza, H., Teo, J. D., Wu, B. and Macary, P. A. (2010) Current views on the clinical relevance of Blastocystis spp. Current Infectious Disease Reports 12, 28-35.

Tan, K. S. W. (2004). Blastocystis in humans and animals: new insights using modern methodologies. Veterinary Parasitology 126, 121-144.

Tan, K.S. W. (2008). New insights on classification, identification, and clinical relevance of Blastocystis spp. Clinical Microbiology Reviews 21, 639-665.

Tasova, Y., Sahin, B., Koltas, S. and Paydas, S. (2000). Clinical significance and frequency of Blastocystis hominis in Turkish patients with hematological malignancy. Acta Medica Okayama 54, 133-136.

Yaicharoen, R., Ngrenngarmlert, W., Wongjindanon, N., Sripochang, S. and Kiatfuengfoo, R. (2006). Infection of Blastocystis hominis in primary schoolchildren from Nakhon Pathom province, Thailand. Tropical Biomedicine 23, 117-122.

Yoshikawa, H., Abe, N. and Wu, Z. (2004). PCR-based identification of zoonotic isolates of Blastocystis from mammals and birds. Microbiology 150, 1147-1151.

Yoshikawa, H., Wu, Z., Nagano, I. and Takahashi, Y. (2003). Molecular comparative studies among Blastocystis isolates obtained from humans and animals. Fournal of Parasitology 89, 585-594.

Yoshikawa, H., Wu, Z., Pandey, K., Pandey, B. D., Sherchand, J. B., Yanagi, T. and Kanbara, H. (2009). Molecular characterization of Blastocystis isolates from children and rhesus monkeys in Kathmandu, Nepal. Veterinary Parasitology 160, 295-300.

Zaman, V., Howe, J. and Ng, M. (1995). Ultrastructure of Blastocystis hominis cysts. Parasitology Research 81, 465-469. 